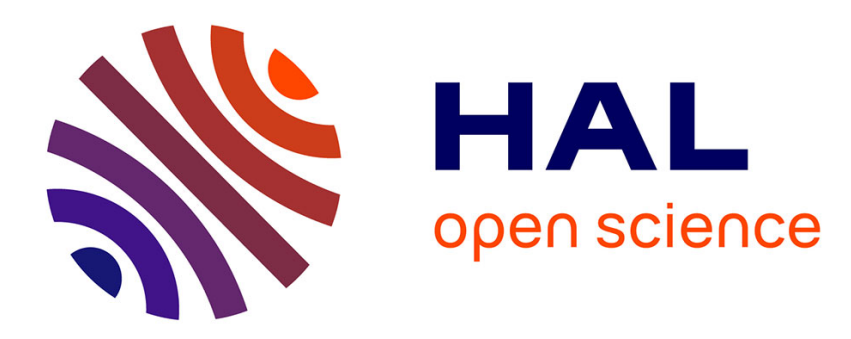

\title{
WIM data to assess consequences of new traffic regulations
}

\author{
Franziska Schmidt, Bernard Jacob
}

\section{To cite this version:}

Franziska Schmidt, Bernard Jacob. WIM data to assess consequences of new traffic regulations. The Fifth International Conference on Bridge Maintenance, Safety and Management, IABMAS 2010, Jul 2010, France. 6p. hal-00949085

\section{HAL Id: hal-00949085 https://hal.science/hal-00949085}

Submitted on 19 Feb 2014

HAL is a multi-disciplinary open access archive for the deposit and dissemination of scientific research documents, whether they are published or not. The documents may come from teaching and research institutions in France or abroad, or from public or private research centers.
L'archive ouverte pluridisciplinaire HAL, est destinée au dépôt et à la diffusion de documents scientifiques de niveau recherche, publiés ou non, émanant des établissements d'enseignement et de recherche français ou étrangers, des laboratoires publics ou privés. 


\title{
WIM data to assess consequences of new traffic regulations
}

\author{
F. Schmidt \& B. Jacob \\ Laboratoire Central des Ponts et Chaussées, France
}

\begin{abstract}
Bridge code calibration and assessment of existing bridges require an accurate knowledge of traffic load patterns. WIM data are useful for these applications, either to account for the current traffic loads or to assess the potential impact of future loads. Traffic load effects were calculated on two composite bridges, using WIM data of a French motorway, and the effect of an increase of the gross weight limit from 40 to 44 tons was assessed by a micro-simulation. Extreme values and fatigue lifetimes are calculated and compared for the current traffic and a traffic with the increased weight limit. The lifetime of details sensitive in fatigue could be decreased by $20 \%$ if the weight regulation is changed.
\end{abstract}

\section{INTRODUCTION}

Bridge load effects, stresses or damage and lifetime in fatigue are assessed either by measurements, using stain gauges, extensometers and other techniques, or by calculation, using traffic load data and bridge models such as influence line or surfaces, if the dynamic interactions are neglected (Bailey \& Bez 1996, Nassif \& Nowak 1996, Jacob 1998, Jacob \& Labry 2002). The development and implementation of WIM techniques allowed to collect traffic load data on a large scale and to use them for bridge assessment (Jacob et al. 2002), instead of using simulated data (Hwang \& Nowak 1991).

In the late 1980's and early 1990's, some extensive works were developed in Europe using traffic data of various EU member states (Vrouwenvelder \& Waarts 1993, Bruls et al. 1996, O’Connor et al. 1998) to design the Eurocode "Traffic loads on bridges" (CEN EN1991-2, 2003). Extreme loads and load effects were considered to calibrate the general load models (Flint \& Jacob 1996) and fatigue calculation were performed to design the fatigue load models (Jacob \& Kretz 1996).

All these models and assessment methods assume that the traffic loads and models (Ditlevsen 1994) are stationary. But the traffic loads and volume increase with time because of the development of the road freight transport, and the increases of the truck legal weight limits. Thus it is necessary to periodically re-calibrate the bridge code load models and to re-assess the reliability of existing bridges against the traffic loads. That is one of the goal of the WIM systems installed all around the world on highways and motorways. The methodology and some tools are briefly reported here, and an application to the assessment of possible consequences of an increase of the truck gross weight limit in France from 40 to 44 tons is presented.

\section{WIM DATA}

Traffic data and loads are collected in France for bridge engineering by WIM systems since the early 1980's. However, with the recent development of a national WIM network for overload screening and enforcement (Marchadour \& Jacob 2008), more reliable and accurate data are collected continuously on the main highways and motorways. The traffic data used in this study were collected on two adjacent traffic lanes of the French motorway A9 near Montpellier in South France, over a month in June 2009. Figure 1 shows the gross vehicle weight distributions on the slow lane over one and two weeks.

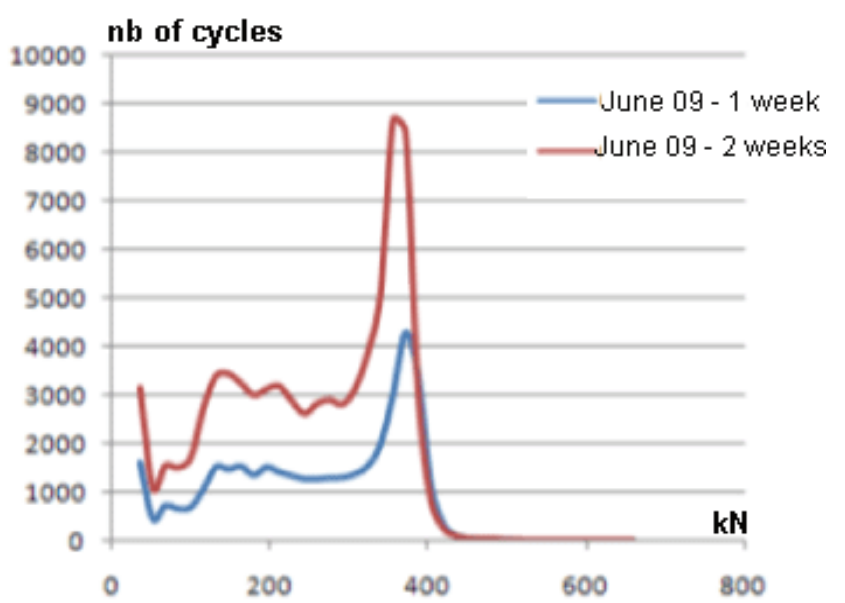

Figure 1. Gross weight distributions on the slow lane of the A9 motorway, 1 \& 2 weeks in June 2009.

Axle loads and spacing, speed and time of passage in $1 / 100 \mathrm{~s}$ are also recorded for each truck in both lanes. The accuracy of these data are at least in class $\mathrm{C}(15)$, but mostly in class $\mathrm{B}(10)$ of the European specifications of WIM (Jacob et al. 2002), i.e. app. $95 \%$ of the gross weights are within $\pm 10 \%$ and of axle loads within $\pm 15 \%$ of the static values taken as the reference. 


\section{CALCULATION TOOLS}

\subsection{Influence lines}

The effects of traffic on a bridge are usually calculated by applying traffic loads, either measured by WIM systems or simulated by software, on influence lines or surfaces. For local effects sensitive to the wheel transverse location, WIM data shall contain this information and an accurate influence surface, i.e. a two-dimensional calculation, must be used. For most of the global or semi-global and longitudinal effects, such as bending moments at mid-span or on pier, shear forces or pier reactions, one or a set of parallel longitudinal influence lines (one per traffic lane) are sufficient, and the traffic data lane by lane are used. That is the case in this study.

The influence lines or surfaces are obtained numerically, through 1-D bridge model or 2-D finite elements calculations, or on site through experimentation (by strain measurement on a bridge under a known truck). In this later case, several parameters are taken into account, such as the stiffness of the pavement surface, sidewalks and safety barriers, that are neglected in the numerical method.

The effects considered in this study are, for two bridges:

- The bending moment stress at mid-span of a simple supported $40 \mathrm{~m}$ span bridge, near Auxerre. This is a composite bridge with two main steel girders and a concrete deck.

- The bending moment stress at mid-spans and on piers of the Libourne 4-span bridge (respectively $48,60,60$ and 48 meters-long). This is also a 2steel girder composite bridge.

The influence lines are given in $\mathrm{MPa} / \mathrm{MN}$ in Figures 2 and 3. The dominant effects are in the lower flange at mid-span and in the upper flange on pier. These influence lines are those calculated for a load applied along a steel girder. To obtain the influence surface, they have to be combined with the transverse influence line, given by Courbon's coefficient.

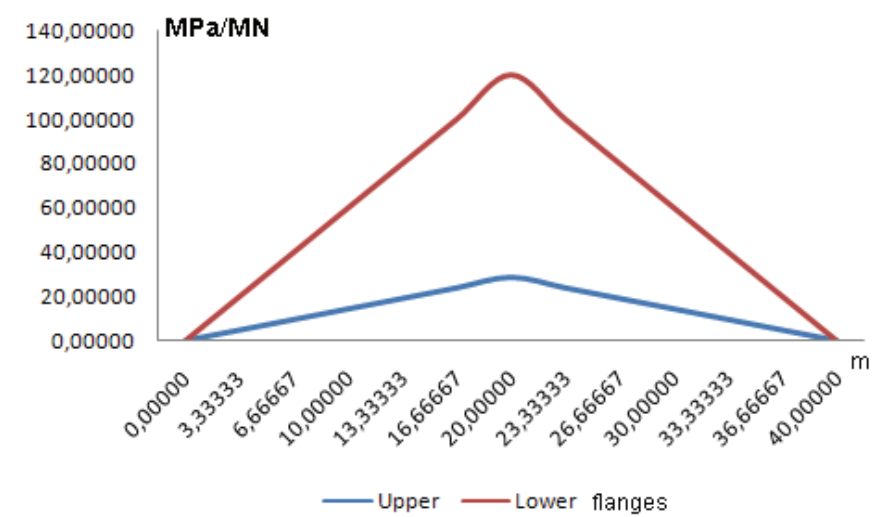

Figure 2. Influence line of the bending moment stress at midspan of the lower flange of a girder, Auxerre composite bridge.

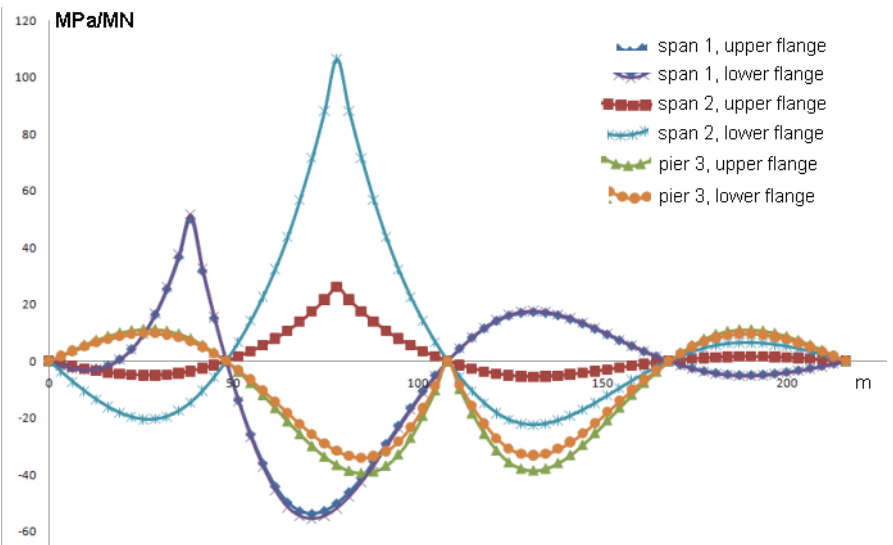

Figure 3. Bending moment stress influence lines at mid-span and on piers of the upper and lower flanges, Libourne bridge.

\subsection{Traffic data adaptation}

The WIM data presented in section 2 contain two adjacent lanes in the same direction, i.e. one slow lane and one fast (passing) lane. Auxerre bridge supports 3 traffic lanes (each $3.50 \mathrm{~m}$ in width), including 2 slow lanes (one in each direction) and one fast passing lane. Libourne bridge has 2 slow lanes (one in each direction).

Thus, the recorded data are adapted to fit to the bridge operation conditions. The natural data of the slow lane are applied on one slow lane of each bridge, and the data of the fast lane on the fast lane of Auxerre. The slow lanes in the other direction are filled with the slow lane data shifted by 10 minutes, which simulate a traffic correlated (same peak and low hours) but with independent trucks.

\subsection{CASTOR and POLLUX softwares}

The POLLUX software, developed by the LCPC, is a new and extended version of the former CASTOR software (Eymard \& Jacob 1989). It uses WIM data and load effect or stress influence lines of any bridge, and calculates the effects of the whole traffic on this bridge (Figure 4). The traffic record may be on one lane or on multiple lanes, and the software may use one influence line per lane, or an influence surface for the whole deck.

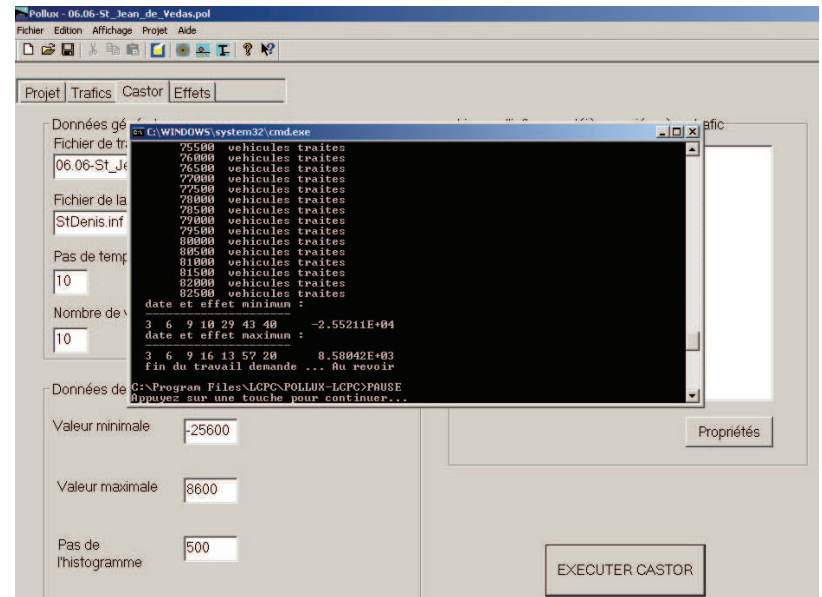

Figure 4. Software POLLUX: main screen and parameters. 
Different modules of POLLUX perform successive tasks:

- Traffic data cleaner: the traffic data files, provided by WIM systems, are first checked and cleaned if necessary. If some anomalies are detected, the involved vehicles are deleted. For example, vehicles with a length below $1.5 \mathrm{~m}$ or over $25 \mathrm{~m}$, or with only one axle or more than 8 axles, are eliminated. If the gap between two successive vehicles is greater than 90 minutes, the system is assumed to have failed and the time period is deleted. All these limits are defined by the user.

- CASTOR, which became a sub-routine of POLLUX, calculates the effects of the traffic loads. For each effect (set of influence lines for each traffic lane), the time history of the effect is calculated with a constant time step, chosen by the user with respect to the influence line shape. All the vehicles are assumed to be at a constant speed of $20 \mathrm{~m} / \mathrm{s}$. Thus for a $100 \mathrm{~m}$ bridge length, to sample the influence line by steps of $1 \mathrm{~m}$, the time step will be $0.05 \mathrm{~s}$. The output of CASTOR is a set of three histograms, which represent the variations of the effects: (i) the mini-max histogram (successive local minima and maxima), (ii) the level crossing histogram, and (iii) the rainflow histogram (AFNOR 1993), only used for fatigue assessment. The class width of these histograms are chosen by the user.

- The sub-routine "Extrap" extrapolates the traffic load effects over any time period longer than the traffic record period, assuming that the traffic is stationary, as explained in section 4.1.

- The sub-routine "Durvie" calculates the damage and lifetime in fatigue, for a detail submitted to the stress history resulting of the traffic loads applied to a stress influence line, as explained in section 4.2 .

\section{EXTREME EFFECTS AND FATIGUE}

This section describes the methods used by CASTOR and POLLUX to extrapolate the extreme effects and to calculate bridge lifetime in fatigue.

\subsection{Extreme extrapolated effects}

The extreme load effects or stresses over the whole planned or conventional lifetime of a bridge, are necessary to calibrate the bridge code load models or to assess the reliability of a bridge submitted to traffic loads. Depending on the considered limit state ultimate or serviceability limit state - and the human or economical consequences of the bridge or part of a bridge failure, and on the status of the traffic action - main action or secondary action in a combination of actions -, an adapted return period is chosen.
The return period $R_{x}$ of $x$ for a random variable $\mathrm{X}$, which is assumed to represent successive independent occurrences of a random phenomenon, is the mean time period between two occurrences of $x$. It may be proved that if $\mathrm{P}\left[\operatorname{Max}_{1 \leq i \leq N}\left(\mathrm{X}_{\mathrm{i}}\right)<x_{\alpha}\right]=\alpha$,

$$
R_{x_{\alpha}} \approx \frac{-N}{\ln (1-\alpha)} \approx \frac{N}{\alpha}
$$

if $N \rightarrow+\infty$, and then if $N \rightarrow+\infty$ and $\alpha \rightarrow 0$.

The return period for the traffic load characteristic value is 2000 years in the Eurocode, which corresponds to a probability $\alpha=5 \%$ to be exceeded in a lifetime $N=100$ years.

The traffic load effect extrapolation method was initially proposed by (Jacob et al. 1989). It consists in fitting the upper part of a Gaussian distribution to the upper tail of the level crossing histogram and then using the Rice formula (Rice 1954). The traffic load effect is assumed to be stationary and Gaussian (Ditlevsen 1994), and thus the mean rate $v(x)$ of upcrossings the level $x>0$ is given by:.

$v(x)=\frac{1}{2 \pi} \frac{\sigma}{\sigma} \exp \left(-\frac{(x-m)^{2}}{2 \sigma^{2}}\right)$ (Rice formula)

where $\sigma, \dot{\sigma}$ and $m$ are respectively the standard variation of $X, \dot{X}$ and the mean of the process. Then it may be shown that:

$v(x) R_{t}=1 \Rightarrow x=m \pm \sigma \sqrt{2 \ln \left(v_{0} R_{t}\right)}$.

The user chooses a return period and a confidence level for the Kolmogorov test applied to check the fit of the Gaussian distribution on the upper tail of the level crossing histogram (Cremona 2001). Then the value $x$ with the chosen return period $R_{t}$ is given by Equation 3 .

\subsection{Fatigue}

The fatigue damage $D$ of a detail is assessed using Miner's rule:

$$
D=\sum_{\Delta \sigma_{i}=0} \frac{n_{i}}{N_{i}}
$$

where $n_{i}$ is the number of cycles in the class $\Delta \sigma_{i}$ of the stress rain-flow histogram; $N_{i}$ is the number of cycles at failure corresponding to $\boldsymbol{\Delta} \sigma_{i}$ in the S-N (Wöhler) two slope curve defined by:

$$
\left\{\begin{array}{c}
N \cdot \Delta \sigma^{3}=5.10^{6} . \Delta \sigma_{D}{ }^{3} \text { if } \Delta \sigma \geq \Delta \sigma_{D} \\
N \cdot \Delta \sigma^{5}=5.10^{6} . \Delta \sigma_{D}{ }^{5} \text { if } \Delta \sigma_{D}>\Delta \sigma \geq \Delta \sigma_{L} \\
N=\infty \text { if } \Delta \sigma_{L}>\Delta \sigma
\end{array}\right.
$$

in the Eurocode 1993 Part 1-9 (CEN EN 1993-1-9, 2005), $\Delta \sigma_{L}$ corresponds to $N_{L}=10^{2}$ cycles, so $\boldsymbol{\Delta} \sigma_{L}=0.55 \boldsymbol{\Delta} \sigma_{D}$. The conventional lifetime (in years) of the detail is $1 / T D$, where $T$ is the length of the time period which corresponds to the rain-flow histogram. 
5 COMPARISON OF TRAFFIC LOAD EFFECTS DEPENDING ON THE WEIGHT LIMIT

\subsection{Weight limits in the current French legislation and future plans}

In France, and in Europe for international transport, the standard gross vehicle weight limit is 40 tons. Some countries allow higher weights, such as 44 tons in the UK for 6-axle articulated trucks. In France, there are a couple of derogations which allow 44 tons for 5-axle articulated trucks if: (i) $40 \mathrm{ft}$ containers are transported in a multi-modal journey, (ii) the freight comes from or goes to a maritime or inland harbor, where it is carried by ship, (iii) some specified agricultural goods are transported during specific seasons. Moreover, log trucks are allowed up to 48 tons on 5 axles and 57 tons on 6 axles by decree.

In 2008, the French parliament voted a law called "Grenelle de l'environnement" to reduce the CO2 emissions and the fossil energy consumption. An article stated that road transport regulation shall be adapted for that. In February 2009, the parliament asked to the government to study the positive and negative impacts of increasing the gross weight limit to 44 tons. The main criteria to consider were road safety, CO2 emission and energy consumption, traffic congestion, and infrastructure (bridges and pavement...) lifetime and maintenance.

\subsection{Impact of 44 trucks on traffic and bridges}

For bridges, the first task was to compare the effects of a single $44 \mathrm{t}$ truck to those of a $40 \mathrm{t}$ truck. Because the axle load limit would not be increased, only medium span (15 to $40 \mathrm{~m}$ ) bridges could be affected, or $10 \mathrm{~m}$ continuous span bridge for bending moment on pier. Shorter spans could not support a whole truck at once. Longer spans are not so much sensitive to a single truck. For medium span bridges, the load effects would be increased by less than $10 \%$, which is not too much critical for the extreme loads and load effects on healthy bridges. However, the impact of multiple presences (truck crossing or overtaking) of $44 \mathrm{t}$ trucks, or the effect on the fatigue lifetime was to be investigated more in depth.

Therefore, it is necessary to make some assumption on how the whole traffic would change with new regulations and to assess the effects of this whole new traffic. The very simple and crude assumptions done here are: (i) the gross weight of every heavy vehicle laying between 36 and 44 tons would be increased by $10 \%$, the additional weight being uniformly distributed on all axes; (ii) all the other vehicles would have the same load as before (volume limitation or not enough freight to carry).

With these assumptions, a micro-simulation generated a "modified" traffic file named " $44 \mathrm{t}$ " derived from the natural traffic record of the WIM system on the A9 motorway, named " $40 \mathrm{t}$ ". Both traffics were used with the influence lines introduced in the section 3.1, to obtain the effects and their histograms.

\subsection{Extreme load effects}

The minimum and maximum bending moment stresses induced in the lower flange of a main girder of Auxerre bridge under the two week traffic of the A9 motorway are given in Table 1, for the natural traffic and for the modified traffic with 44 ton trucks. The minimum values are negative because of the Courbon's coefficient of the opposite lane of the considered girder. With the 44 ton truck modified traffic, the extreme values computed are increased by $6.5 \%$ (minimum) and $8.5 \%$ (maximum), i.e. less then the gross weight increase of the fully loaded trucks, because these extreme values are obtained while two trucks are crossing each other, one of them may exceed the legal load.

Using the level crossing histogram of the same effect, and the Rice formula as explained in section 4.1 , the minimum and maximum values are extrapolated for return periods of 25, 50, 500, 1000 and 5000 years (Table 2). For the three chosen Kolmogorov thresholds, $\beta=0.9, \beta=0.95$ and $\beta=0.99$, the extrapolated values are the same; that means that the simulations has converged (Cremona 2001). The maximum stresses for a 2000 year return period, as specified in the Eurocode 0 (CEN EN1990, 2002) for traffic load characteristic values, are close to 100 $\mathrm{MPa}$, which seems to be coherent with the bridge design. However, the real local traffic on this bridge is much lower and lighter than the A9 motorway traffic.

Table 1. Extrema of the computed stresses, Auxerre, main girder mid-span bending moment, lower flange, A9 traffic and modified traffic with 44 ton trucks ( 2 weeks).

\begin{tabular}{lcc}
\hline & $\sigma_{\min }(\mathrm{MPa})$ & $\sigma_{\max }(\mathrm{MPa})$ \\
\hline 40 tons & -6.1 & 35.3 \\
44 tons & -6.5 & 38.3 \\
\hline
\end{tabular}

Table 2. Extrapolated minimum and maximum stresses, Auxerre, mid-span bending moment, lower flange, A9 traffic, for different return periods.

\begin{tabular}{ccc}
\hline $\mathrm{R}_{\mathrm{t}}(\mathrm{yrs})$ & $\sigma_{\min }(\mathrm{MPa})$ & $\sigma_{\max }(\mathrm{MPa})$ \\
\hline 25 & -6.1 & 67.2 \\
50 & -6.7 & 74.1 \\
500 & -7.1 & 93.4 \\
1000 & -7.3 & 98.5 \\
5000 & -7.6 & 109.3 \\
\hline
\end{tabular}

\subsection{Fatigue damage}

To assess the fatigue damage and detail lifetime, the rain-flow histograms are used, with the S-N curves and the Miners' law (section 4.2). Figure 5 gives the 
rain-flow histograms of the bending moment stresses in the lower flange at mid-span for both traffics ( 40 tons and 44 tons) on Auxerre bridge. An increase of $10 \%$ of the peak abscissa ( 18 to $20 \mathrm{MPa}$ ) is visible when the 44 ton trucks are introduced. Reversely, the distribution shows a drop at $18 \mathrm{MPa}$ in this case, because truck gross weights between 36 and 40 tons were increased by $10 \%$, and thus, there are no more trucks in this weight interval.

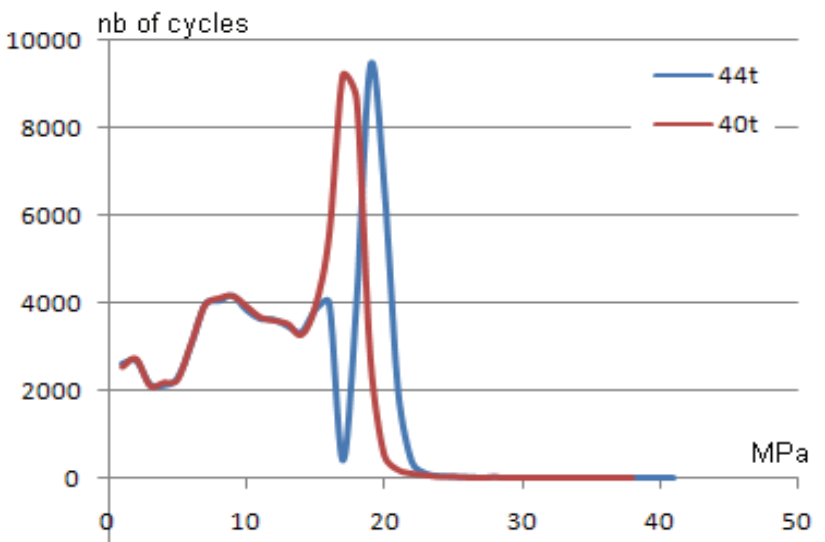

Figure 5. Rain-flow distributions of the stresses in Auxerre bridges at mid-span, lower flange, both traffics.

Then the fatigue damage is calculated for the S-N curves 56, 63 and $71 \mathrm{MPa}$ (Table 3). The detail is classified in class 71 but the flange is $70 \mathrm{~mm}$ in thick, and therefore a reduction factor of: $\sqrt[4]{25 / 70}=0.77$ leads to the class 56 .

The annual damage is obtained by multiplying the weekly damage by 50 . The conventional lifetime is the inverse of the annual damage. The lifetimes for Auxerre bridge are given in Table 3 for both traffics. The values are very short, but the traffic of the A9 motorway, one of the busiest in France, is much more severe than the local traffic around Auxerre. The most important finding is the reduction of the lifetime by almost $20 \%$ when the 44 ton trucks are introduced. That gives an estimation of the effect of such a change in the regulation for bridges.

Table 3. Auxerre bridge lifetime for A9 traffic, 40 or 44 t gross weight limit.

\begin{tabular}{llr}
\hline & \multicolumn{2}{c}{ Lifetimes (in years) } \\
\cline { 2 - 2 } Fatigue class & 40 tons & 44 tons \\
\hline Class 56 & 10.1 & 8.5 \\
Class 63 & 14.3 & 12.0 \\
Class 71 & 20.1 & 16.9 \\
\hline
\end{tabular}

Similar results are given for Libourne bridge, and more precisely for the weld of the vertical stiffener on the girder lower flange at mid-span of the first span. The fatigue class is 60 after the reduction due to the flange thickness. The calculated lifetimes are given in Table 4 for both traffics. The lifetime with the natural traffic is app. 55 years, and reduced to 45 years with the 44 ton trucks.
Table 4. Libourne bridge lifetime, $1^{\text {st }}$ span, bending moment of the lower flange, for A9 traffic, 40 or 44 t gross weight limit.

\begin{tabular}{llll}
\hline & \multicolumn{2}{c}{ Lifetimes (in years) } \\
\cline { 2 - 2 } Fatigue class & 40 tons & 44 ton \\
\hline Class 50 & 34.6 & 28.9 \\
Class 56 & 48.9 & 40.8 \\
Class 63 & 69.0 & 58.8 \\
\hline
\end{tabular}

These calculations show a decrease of the lifetime by app. $20 \%$ with the 44 ton trucks, as with Auxerre bridge.

\section{CONCLUSIONS}

Bridge code calibration as well as assessment or reassessment of existing bridges under traffic loads require an accurate knowledge of the load patterns. WIM data are very useful for these applications, either to give an account of the current traffic loads or to forecast the potential impact of future loads.

With the computer software POLLUX developed in the LCPC, the stresses induced in a fatigue sensitive detail of two composite bridges, the weld between a vertical stiffener and the lower flange of a main girder, were calculated. The traffic of a heavy trafficked motorway in south of France, measured over two weeks by an accurate WIM system, was used. The same traffic was then modified to account for a possible change in the gross weight limit in the French law, being increased from 40 to 44 tons for articulated 5-axle trucks and road trains. Extrapolated extreme values and lifetime in fatigue were calculated for both traffics and bridges.

The increase of the extreme stresses was limited to 6.5 or $8.5 \%$, on a $40 \mathrm{~m}$ simple supported span (bending moment at mid span effect), carrying three traffic lanes. The multiple presence of more than one truck in adjacent lanes and the passage of exceptional or overloaded trucks explain that this increase is less than $10 \%$ ( 40 to $44 \mathrm{t}$ ).

The computed lifetimes in fatigue for both bridges are rather short, because the real traffics on these bridges are local traffics and much lighter than the motorway A9 one. However, the reduction of the lifetime, whatever the fatigue resistance (S-N class) and the bridge, is close to $20 \%$. This value seems reasonable because of the non linearity of the fatigue damage with the load, while not all of the trucks are affected by the weight increase. Moreover, the carriers claim that increasing the weight limit by $10 \%$ would slightly reduce the number of trucks on the roads. Thus, we can estimate the lifetime reduction for fatigue sensitive bridges between 10 and $20 \%$, if the weight regulation is changed. 


\section{REFERENCES}

AFNOR (1993). Fatigue sous sollicitations d'amplitude variable. Méthode rain-flow de comptage des cycles. A03-406. Norme française.

Bailey, S.F. \& Bez, R. (1996), Site Specific Traffic Load Models, $7^{\text {th }}$ International Conference on Applications of Statistics and Probability in Civil Engineering, ICASP 7, vol. 3, AA Balkema, Rotterdam.

Bruls, A., Croce, P., Sanpaolesi, L. \& Sedlacek, G. (1996). EVN1991-Part 3: Traffic Loads on Bridges; Calibration of Load Models for Road Bridges, Proceedings of IABSE Colloquium, Delft, The Netherlands, IABSE, 439-453.

CEN EN1990 (2002). Eurocode 0: Basis of structural design.

CEN EN1991-2 (2003). Eurocode 1: Actions on structures Part 2: Traffic loads on bridges.

CEN EN1993-1-9 (2005). Eurocode 3: Design of steel structures - Part 1-9: Fatigue strength of steel structures.

Cremona, C. (2001). Optimal extrapolation of traffic load effects. Structural Safety (23): 31-46.

Ditlevsen, O. (1994). Traffic loads on large bridges modeled as white noise fields. ASCE Journal of Engineering Mechanics 120(4): 681-694.

Eymard, R. \& B. Jacob (1989). Un nouveau logiciel : le programme CASTOR pour le Calcul des Actions et Sollicitations du Trafic dans les Ouvrages Routiers. Bulletin de liaison des laboratoires des Ponts et Chaussées (164): 64-78.

Flint, A. \& Jacob, B., (1996), Extreme Traffic Loads on Road Bridges and Target Values of their Effects for Code Calibration, Proceedings of IABSE Colloquium Basis of Design and Actions on Structures, IABSE, Delft, 469-477.

Hwang, E.S. \& Nowak, A.S. (1991). Simulation of dynamic load for bridges. Journal of structural engineering, ASCE, vol 119, 6, 853-867.

Jacob, B., Maillard, J.B. \& Gorse, J.F. (1989). Probabilistic traffic load models and extreme loads on a bridge, Proceedings of ICOSSAR'89, 1973-1980.

Jacob, B. (1998), Application of weigh-in-motion data to fatigue of road bridges, Pre-Proceedings of the Second European Conference on WIM of Road Vehicles, eds O'Brien and Jacob, Lisbon, European Commission, Luxembourg, 214-229.

Jacob, B. \& Kretz, T. (1996). Calibration of bridge fatigue loads under real traffic conditions. Proceedings of the IABSE Colloquium on Eurocodes, Delft, March, 479-487.

Jacob, B., OBrien, E.J. \& Jehaes, S. (eds.) 2002. Weigh-inMotion of Road Vehicles: Final Report of the COST 323 Action, LCPC Publications, Paris, 535 pp.

Jacob, B. \& Labry, D. (2002). Evaluation of dynamic effects of heavy vehicles on bridge fatigue, Proceedings of $7^{\text {th }}$ International Symposium on Heavy Vehicle Weights \& Dimensions, Delft, The Netherlands, June.

Marchadour, Y. \& Jacob, B. (2008). Development and implementation of a WIM network for enforcement in France, Proc. of the International Conference on Heavy Vehicles ICWIM5, eds. B. Jacob et al., ISTE/J. Wiley, 335-346.

Nassif, H.H. \& Nowak, A.S. (1996). Dynamic load for girder bridges under normal traffic. Archives of civil engineering, XIII, 4.

O'Connor, A.J., Jacob, B., O'Brien, E.J. \& Prat, M. (1998). Effects of traffic loads on road bridges - Preliminary studies for the re-assessment of the traffic load model for Eurocode 1 Part 3. Pre-Proceedings of the Second European Conference on WIM of Road Vehicles, eds O'Brien and Jacob, Lisbon, European Commission, Luxembourg, 231-242.

Rice, S., Ed. (1954). Mathematical analysis of random noise. Selected Papers in Noise and Stochastic Processes New York : Dover.
Vrouwenvelder, A. \& Waarts, P.H. (1993). Traffic Load on bridges, Structural Engineering International, 169-177. 